\title{
Patient Preference and Adherence to
}

\section{Aminosalicylates for the Treatment of Ulcerative Colitis}

\author{
Kartikeya Tripathi ${ }^{1}$ \\ Jeffrey Dong $\mathbb{( D}^{2}$ \\ Brooke F Mishkin ${ }^{2}$ \\ Joseph D Feuerstein ${ }^{2}$ \\ 'Department of Gastroenterology, \\ University of Massachusetts Medical \\ School - Baystate Campus, Springfield, \\ MA, USA; ${ }^{2}$ Division of Gastroenterology, \\ Beth Israel Deaconess Medical Center, \\ Harvard Medical School, Boston, \\ MA, USA
}

\begin{abstract}
Ulcerative colitis (UC) is a chronic inflammatory disorder that requires sustained treatment for optimal outcomes. The 5-aminosalicylate (5-ASA) class of medications are first-line for the treatment of mild-to-moderate UC but suffer from suboptimal adherence rates in real-world settings. This review summarizes the literature on adherence and patient preference to 5-ASA in patients with UC. We begin by highlighting key studies that measure real-world adherence rates, as well as some of the pitfalls associated with certain techniques. We examine the data on the consequences of non-adherence, which range from decreased quality of life and higher risk of colorectal cancer at the individual level to increased costs to the overall healthcare system. We then turn to the reasons and risk factors for non-adherence and summarize the current understanding of the barriers towards adherence. Afterwards, we describe the research on patient preferences between 5-ASA formulations and dosing regimen. Finally, we summarize the evidence regarding interventions to improve 5-ASA adherence. While adherence remains a challenge in practice, understanding the current state of the field can better inform future efforts towards increasing adherence, and thus clinical outcomes, in UC.
\end{abstract}

Keywords: UC, 5-ASA, ulcerative colitis, adherence, compliance

\section{Introduction}

Ulcerative colitis (UC) is an idiopathic, chronic inflammatory disorder of colonic mucosa that commonly involves the rectum and may extend proximally in a continuous fashion throughout the colon. ${ }^{1}$ It is one of the two major forms of inflammatory bowel disease (IBD), and it is classified from mild to severe based on Truelove and Witts criteria and the Mayo Clinic score. ${ }^{2-4}$ Globally, there were an estimated 6.8 million cases of IBD in 2017, with the highest incidence in highincome North America. ${ }^{5}$ As more countries adopt a Western lifestyle, the prevalence, and thus total disease burden, of $\mathrm{UC}$ is projected to continue to rise.

One of the first effective types of medication to treat UC is the 5-aminosalicylates (5-ASA) class, which includes sulfasalazine, mesalamine, and diazo-bonded 5-ASA. ${ }^{4}$ Sulfasalazine, which consists of 5-ASA bonded to sulfapyridine, was the first to be discovered but is no longer routinely used owing to the side effects of sulfapyridine. Mesalamine has been packaged into various formulations, such as enteric-coated tablets and multi-matrix (MMX) formulations, to deliver the medication into the lower bowel, while diazo-bonded 5-ASA are prodrugs which are converted to 5-ASA by colonic bacteria (Table 1). In addition to oral formulations, mesalamine has also been packaged
Correspondence: Joseph D Feuerstein Division of Gastroenterology, Beth Israel Deaconess Medical Center, Harvard Medical School, 110 Francis St 8e Gastroenterology, Boston, MA, 02215, USA

Tel + I 6176328623

$\mathrm{Fax}+16176329199$

Email Jfeuerst@bidmc.harvard.edu 
Table I Available 5-ASA Formulations, Mechanisms of Delivery, and Dosing

\begin{tabular}{|c|c|c|c|c|c|}
\hline Formulation & $\begin{array}{l}\text { Generic } \\
\text { Name }\end{array}$ & $\begin{array}{l}\text { Trade } \\
\text { Names }\end{array}$ & Mode of Activation & $\begin{array}{l}\text { Site of } \\
\text { Delivery }\end{array}$ & Daily Dosing \\
\hline \multirow[t]{3}{*}{ Diazo-bonded } & Sulfasalazine & $\begin{array}{l}\text { Azulfidine, } \\
\text { Salazopyrin* }\end{array}$ & Mesalamine bound to sulfapyridine & Colon & $\begin{array}{l}4 \text { grams per day in three to } \\
\text { four divided doses }\end{array}$ \\
\hline & Olsalazine & Dipentum & Two mesalamine molecules bound together & Colon & $\begin{array}{l}\text { I gram daily in two divided } \\
\text { doses }\end{array}$ \\
\hline & Balsalazide & $\begin{array}{l}\text { Colazide, } \\
\text { Colazal }\end{array}$ & $\begin{array}{l}\text { Mesalamine bound to } 4 \text {-aminobenzoyl- } \beta \text { - } \\
\text { alanine }\end{array}$ & Colon & $\begin{array}{l}2.25 \text { to } 6.75 \text { grams daily in } \\
\text { three divided doses }\end{array}$ \\
\hline $\begin{array}{l}\text { Delayed } \mathrm{pH} \\
\text { mediated } \\
\text { release }\end{array}$ & Mesalamine & $\begin{array}{l}\text { Asacol, } \\
\text { Delzicol }\end{array}$ & Eudragit-S coating (dissolves at $\mathrm{pH} \geq 7$ ) & $\begin{array}{l}\text { Mid-terminal } \\
\text { ileum to colon }\end{array}$ & $\begin{array}{l}\text { I.6 to } 2.4 \text { grams daily in one } \\
\text { to three divided doses }\end{array}$ \\
\hline $\begin{array}{l}\text { Multi-matrix } \\
\text { system }\end{array}$ & $\begin{array}{c}\mathrm{MMX} \\
\text { mesalamine }\end{array}$ & $\begin{array}{l}\text { Lialda, } \\
\text { Mezavant* }\end{array}$ & $\begin{array}{l}\text { Enteric coating (dissolves at } \mathrm{pH} \geq 7 \text { ). MMX of } \\
\text { lipophilic and hydrophilic excipients }\end{array}$ & $\begin{array}{l}\text { Terminal ileum } \\
\text { and colon }\end{array}$ & 2.4 to 3.6 grams once daily \\
\hline $\begin{array}{l}\text { Time } \\
\text { dependent }\end{array}$ & Mesalamine & Pentasa & $\begin{array}{l}\text { Microspheres encapsulated within an } \\
\text { ethylcellulose semi-permeable membrane }\end{array}$ & $\begin{array}{l}\text { Duodenum to } \\
\text { colon }\end{array}$ & $\begin{array}{l}1.5 \text { to } 4 \text { grams daily in four } \\
\text { divided doses }\end{array}$ \\
\hline
\end{tabular}

Notes: Data from these studies. ${ }^{4,65} *$ Not available in the United States.

Abbreviations: 5-ASA, 5-aminosalicylate; MMX, multi-matrix.

as suppositories, enemas, and foams for rectal use. Despite the difference in delivery modalities, there does not appear to be significant differences in efficacy. ${ }^{6}$ Similarly, aside from sulfasalazine, all 5-ASA formulations are considered extremely safe.

Though the treatment options for UC have increased with the discovery of immunomodulators and biologics, 5-ASA remains the mainstay of treatment for mild-tomoderate UC. The American Gastroenterological Association (AGA) recommends treating patients with mild-to-moderate left sided UC with mesalamine or diazobonded 5-ASA compounds. ${ }^{4}$ For patients with extensive mild-to-moderate UC, the AGA recommends the addition of rectal 5-ASA to oral therapy, as combined oral and rectal therapy delivers a greater effective dose to the affected areas of colon and leads to higher rates of remission. The European Crohn's and Colitis Organization guidelines for using 5-ASA is comparable with AGA guidelines (Table 2). ${ }^{7}$ In practice, over $90 \%$ of patients with UC are treated with 5-ASA shortly after the diagnosis, and most patients who achieve clinical remission with these medications continue them to maintain remission. ${ }^{4,8}$

While a diagnosis of $\mathrm{UC}$ is no longer associated with increased risk of mortality, the morbidity remains significant, with nearly $50 \%$ of patients requiring hospitalization and $10-15 \%$ requiring colectomy by 10 years. $^{8}$ Since mucosal healing is associated with lower risks of complications, adherence to medications plays a crucial role in maintaining remission and improving long-term outcomes of UC. In this review, we describe the risks and outcomes of non-adherence with 5-ASA in UC, factors affecting adherence in UC patients, and patients' preference for treatment with 5-ASA.

\section{5-ASA Adherence in UC}

Medication adherence is an important aspect of inducing and maintaining remission in UC, but it is also a recognized challenge since life-long adherence is required for disease management. While randomized control trials (RCTs) which demonstrated efficacy of 5-ASA compounds often reached adherence rates of $80-90 \%$ owing to strict follow-up and monitoring, experience from other chronic medical conditions indicate that real-world medication adherence rates are approximately $50 \%$ or even lower. ${ }^{9-13}$ Perhaps unsurprisingly, studies examining real-world adherence rates in UC patients have consistently found results much lower than those reported in RCTs.

In 1982, van Hees and van Tongeren demonstrated that $41 \%$ of patients had substantially low serum sulfapyridine levels when measured 1 to 6 months after discharge, despite most claiming that they took sulfasalazine as prescribed. ${ }^{14}$ As the use of sulfasalazine declined, subsequent studies could no longer replicate van Hees and Van Tongeren's methodology to measure adherence. Multiple 
Table 2 Indications to Use 5-ASA Formulations in Patients with Mild to Moderate UC per AGA and ECCO Guidelines

\begin{tabular}{|c|c|c|}
\hline $\begin{array}{l}\text { Disease Site and } \\
\text { Activity }\end{array}$ & AGA & ECCO \\
\hline Proctitis & $\begin{array}{l}\text { Recommends mesalamine enemas (or suppositories) rather } \\
\text { than oral mesalamine, where it also suggests that patients } \\
\text { who place a higher value on convenience of oral medication } \\
\text { administration and a lower value on effectiveness could } \\
\text { reasonably choose oral mesalamine. }\end{array}$ & $\begin{array}{l}\text { Mesalamine I-g suppository once daily is the preferred } \\
\text { initial treatment for mild or moderately active proctitis. } \\
\text { Mesalamine foam or enemas are an alternative. Also, } \\
\text { combining topical mesalamine with oral mesalamine or } \\
\text { topical steroids is more effective. }\end{array}$ \\
\hline $\begin{array}{l}\text { Left-sided mild- } \\
\text { moderate ulcerative } \\
\text { proctosigmoiditis }\end{array}$ & $\begin{array}{l}\text { Oral mesalamine in addition to rectal mesalamine } \\
\text { suppositories or enemas. Combination is more effective than } \\
\text { any form alone. }\end{array}$ & $\begin{array}{l}\text { Active left-sided ulcerative colitis should initially be } \\
\text { treated with an aminosalicylate enema } \geq \mathrm{I} \text { g/day } \\
\text { combined with oral mesalamine } \geq 2.4 \mathrm{~g} / \text { day. }\end{array}$ \\
\hline $\begin{array}{l}\text { Extensive mild- } \\
\text { moderate UC }\end{array}$ & $\begin{array}{l}\text { A standard-dose mesalamine }(2-3 \mathrm{~g} / \mathrm{d}) \mathrm{OR} \text { a diazo-bonded } \\
\text { 5-ASA rather. Low-dose mesalamine, sulfasalazine is not } \\
\text { recommended. } \\
\text { AGA also suggests adding rectal mesalamine to oral 5-ASA in } \\
\text { these patients. }\end{array}$ & $\begin{array}{l}\text { Aminosalicylate enema I g/day combined with oral } \\
\text { mesalamine } \geq 2.4 \mathrm{~g} / \text { day. }\end{array}$ \\
\hline
\end{tabular}

Note: Data from these studies. 4.7.

Abbreviations: 5-ASA, 5-aminosalicylate; UC, ulcerative colitis; AGA, American Gastroenterological Association; ECCO, European Crohn's and Colitis Organization.

authors have used survey-based methods to measure adherence, including Shale and Riley, D'Incà et al, and Moshkovska et al, and have found reported adherence rates to be generally between $50 \%$ and $70 \%$. ${ }^{15-17}$

An important caveat of survey-based methods is that patients tend to over-report their adherence to medications, and indeed other authors have found lower adherence rates when using non-self-reported metrics. ${ }^{18}$ Using prescription refill records, Kane et al calculated an adherence rate of only $40 \%$ among 94 UC patients in remission. ${ }^{19}$ A subsequent study of 1681 patients by Lachaine et al using the Canadian RAMQ database found an even lower adherence rate of $27.7 \%$ at 12 months. ${ }^{20}$ Some authors have also attempted to measure 5-ASA metabolites to increase objectivity; both Shale and Riley and Moshkovska et al incorporated spot urinary 5-ASA and $\mathrm{N}$-acetyl-5-ASA measurements into their studies. ${ }^{15,17}$ However, a subsequent study by Römkens et al found that spot measurements of urinary N-acetyl-5-ASA had considerable intra- and inter-subject variability and was not suitable for assessing 5-ASA adherence in practice. ${ }^{21}$

\section{Implications of Non-Adherence}

Non-adherence has major clinical and economic implications. Multiple studies have shown that non-adherence to 5-ASA significantly increases the risk of relapse. In a pilot 6-month-long RCT of different mesalamine formulations, Kane et al found that 2 of 6 non-adherent UC patients relapsed compared to zero patients who were adherent. ${ }^{22}$ Kane et al also followed a prospective cohort of 99 patients with quiescent UC on 5-ASA for 24 months and found a consistently higher rate of relapse among nonadherent patients, with 13 out of 32 non-adherent patients (40\%) relapsed compared to 6 out of 54 adherent patients (11\%) at 12 months (RR 3.65, 1.54-8.67), and 7 out of 28 non-adherent patients $(25 \%)$ relapsed compared to 1 out of 39 adherent patients $(2.6 \%)$ at 24 months (RR 9.75, 1.2774.9). ${ }^{23}$ Results from a prospective cohort of 104 Japanese patients on 5-ASA were similar, with $41.3 \%$ of nonadherent patients relapsing compared to only $16 \%$ of adherent patients (HR 2.3, 1.004-5.24) by 12 months. ${ }^{24}$

Relapse, in turn, leads to numerous adverse outcomes including but not limited to decreased quality of life, more days missed from work, and adverse pregnancy outcomes. ${ }^{25-}$ ${ }^{28}$ Furthermore, several observational studies have linked 5-ASA non-adherence with an increased risk of colon cancer. Moody et al found that among 175 UC patients, $31.3 \%$ of nonadherent UC patients developed colorectal cancer after 10 years compared to $3.3 \%$ of adherent patients $(\mathrm{p}<0.001) .{ }^{29}$ In a meta-analysis of 9 studies including Moody et al between 1994 and 2004, Velayos et al found a protective association between 5-ASA use and colorectal cancer (OR 0.51, 95\% CI: $0.37-0.69) .{ }^{30}$ Subsequently, van Staa et al showed that IBD patients with regular 5-ASA use was found to have an adjusted OR 0.60 (95\% CI: 0.38-0.96) of developing colorectal cancer compared to those who did not. ${ }^{31}$ 
Furthermore, poor adherence increases healthcare utilization and contributes to higher healthcare expenditures. In a UK-based single-center retrospective cohort study, Bassi et al showed that compared to IBD patients in remission, relapsed IBD patients were associated with a 2- to 3 -fold increase in healthcare costs at baseline and a 20 -fold increase in costs if requiring hospitalization. ${ }^{32}$ Studies using insurance claims data have also linked non-adherence in UC patients to higher costs. Using data from 4313 UC patients from the Maryland CareFirst BlueCross BlueShield program, Kane and Shaya found that patients adherent to 5-ASA incurred $12.5 \%$ lower medical costs than those who were not. ${ }^{33}$ Similarly, an analysis of 1693 UC patients by Mitra et al showed that total all-cause costs were $29 \%$ higher for nonadherent patients. ${ }^{34}$

\section{Factors Affecting Adherence in UC}

In 2003, the World Health Organization (WHO) classified the determinants of non-adherence into five interconnected dimensions, social and economic, health system-related, condition-related, patient-related, and therapy-related (Figure 1) ${ }^{35}$ From a socioeconomic standpoint, the most frequently identified risk factor across multiple studies is younger age. ${ }^{16,17,20,36-39}$ Among 326 patients in the Manitoba IBD Cohort Study, Ediger et al found that $25 \%$ of patients cited cost of medications as an important obstacle towards 5-ASA adherence. ${ }^{36}$ Ediger et al and D'Incà et al also reported an association between being employed and non-adherence, possibly due to the increased time demands associated with employment. ${ }^{16,36}$ Several authors have examined the impact of sex, marital status, and education on 5-ASA adherence, but the association between each of the three variables and adherence have been inconsistent. ${ }^{16,17,19,20,37-40}$

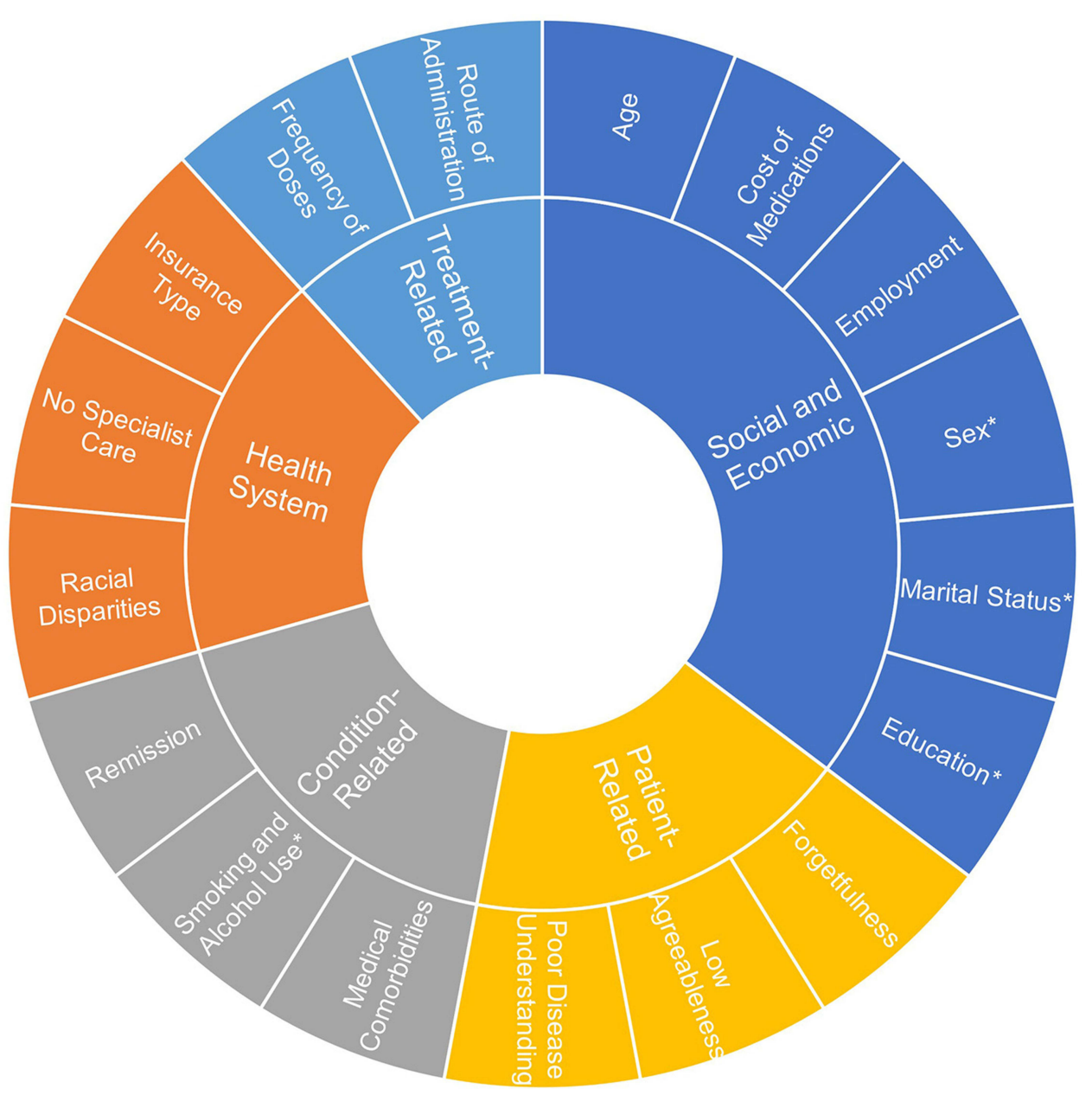

Figure I Factors affecting 5-ASA adherence in patients with UC.

Note: *Factors for which data is conflicting or inconsistent.

Abbreviations: 5-ASA, 5-aminosalicylate; UC, ulcerative colitis. 
The health system that a patient belongs to also plays a significant role on 5-ASA adherence. Through an analysis of claims data from 5664 UC patients in the United States, Yen et al found that patients insured with Medicaid and Medicare risk plans were more likely to be nonadherent to 5-ASA (OR 1.48, 95\% CI 1.03-2.03) compared to those with commercial and fee-for-service Medicare plans. ${ }^{38}$ In addition, those who never receiving specialist care were also more likely to be non-adherent to 5-ASA (OR 1.25, 95\% CI 1.08-1.44). ${ }^{38}$ Nguyen et al has reported disparities in rates of IBD specialist utilization in the United States by race, which by extension suggests that there may be racial disparities in 5-ASA adherence as well. ${ }^{41}$ Lower rates of adherence have also been found among African Americans and Hispanic patients for other chronic medical conditions, further reinforcing that a disparity could exist for 5-ASA adherence as well. ${ }^{42,43}$

From a condition-related perspective, adherence to 5-ASA is impacted by both the natural history of UC as well as the presence of comorbidities. Since UC flares are intermittent, patients may not feel the need to comply with treatment or do not wish to be reminded that they have an underlying chronic disease during remission. ${ }^{20,36}$ In a survey of 485 patients, D'Incà et al reported that nonadherence for patients in remission was $25 \%$, compared to $10 \%$ in those who had active symptomatic disease $(\mathrm{p}<$ $0.001) .{ }^{16}$ Sewitch et al found that overall non-adherence in IBD patients was predicted by disease activity (OR: 0.50 , $\mathrm{p}=0.0022)$ and intentional adherence was predicted by disease duration (OR: 0.12, $\mathrm{p}=0.0001) .{ }^{44}$ In terms of comorbidities, Lee et al described an association between non-adherence and both smoking and alcohol use, though an association between the former and non-adherence was not seen by Cerveny et a ${ }^{37,39}$ While Lachaine et al found no correlation between non-adherence and the diagnosis of another chronic medical condition in claims data, both Kane et al and Ediger et al reported that patients often cite having too many pills to take as a barrier to adherence. ${ }^{23,36}$

Non-adherence to 5-ASA is also shaped by patientrelated factors. Multiple authors, including Kane et al, Ediger et al, and D'Incà et al, have noted that forgetfulness is one of the major reasons patients mention when asked why they do not take their medication. ${ }^{16,23,36}$ Ediger et al also found an association between higher adherence and agreeableness but not with any of the other Big Five personality traits (extraversion, openness, conscientiousness, and neuroticism) ${ }^{36}$ Finally, poor patient understanding of their disease may factor into 5-ASA non-adherence. In studies of UC patients in remission, both Kane et al and Ediger et al observed that a significant number of patients thought that they did not need to take medication while in remission. ${ }^{23,36}$ In interviews with UC patients, Moshkovska et al noted that a poor understanding of the natural history of UC and the benefits of medication, especially during quiescent disease, was a theme among those with low 5-ASA adherence. $^{45}$

\section{Preference Between 5-ASA Formulations}

Given the complex factors which play into non-adherence in the above domains, several authors have investigated whether therapy-related barriers could be minimized by finding formulations and dosing schedules that patients prefer over others. Overall, patients appear to prefer oral over rectal 5-ASA formulations. In a randomized controlled trial, Prantera et al reported a higher rate of adherence to oral 5-ASA compared to rectal therapy $(97.0 \%$ vs $87.5 \%){ }^{46}$ Subsequently, in a real-world setting D'Incà et al found that rectal therapy was associated with greater non-adherence ( $68 \%$ vs $40 \%, p=0.001$ ) owing to discomfort during use and inconvenience of administration. ${ }^{16}$ However, given that in practice rectal 5-ASA is often added for extensive disease or non-response to oral 5-ASA, not all patients may have the opportunity of choosing between oral and rectal therapy.

Dosing frequency may also be important given that patients often cite forgetfulness as reasons for nonadherence. Indeed, experience from other chronic conditions like hypertension, osteoporosis, and HIV demonstrate that decreased dosing frequency leads to higher adherence. ${ }^{47-50}$ Older 5-ASA formulations, including many mesalamine formulations, have traditionally been given multiple times a day in divided doses. In 2003, Kane et al performed a pilot RCT demonstrating that patients with quiescent UC could take mesalamine once-daily and maintain similar rates of remission as those taking the medication in divided doses. ${ }^{22}$ The efficacy of various mesalamine formulations given oncedaily for maintenance of remission was confirmed in several multicenter RCTs, including by Kamm et al, Dignass et al, and Sandborn et al, and notably both Dignass et al and Sandborn et al also found higher rates of satisfaction among patients in the once-daily group. ${ }^{51-53}$ Kruis et al and Flourié et al extended these results to show that mesalamine formulations could also be dosed once-daily for active UC 
with similar rates of remission and similar-to-higher rates of acceptability as divided dosing. ${ }^{54,55}$

\section{Improving 5-ASA Adherence}

Given that patients appear to exhibit a preference towards once-daily 5-ASA, it follows that switching from divided doses to once-daily dosing may lead to increased adherence. Thus, it may be surprising that multiple metaanalyses found no difference in adherence rates between once-daily and divided dose strategies for both induction and maintenance of remission with 5-ASA. ${ }^{6,56,57}$ However, it should be noted that these meta-analyses only included RCTs, where adherence rates in all groups were much higher than real-world rates, and so the effect of dose simplification may have been masked. Results from large-scale retrospective studies by Yen et al and Lachaine et al both showed that patients using MMX mesalamine had higher rates of adherence than patients using other formulations. ${ }^{20,38}$ Since MMX mesalamine was approved with once-daily dosing, in contrast to other 5-ASA formulations, this data may support the superiority of a once-daily strategy if a large portion of patients using non-MMX formulations were being prescribed divided doses. Furthermore, Dignass et al found that despite there being no difference in adherence as measured by amount of medication used, the once-daily group reported lower rates of forgetting to take medications (21-26\% vs $25-44 \%$ in the control group) and had higher rates of remission $(70.9 \%$ vs $58.9 \%, \mathrm{p}=0.024){ }^{52}$ Thus, it is quite plausible that once-daily dosing of 5-ASA can improve adherence, and potentially outcomes.

Other investigators have examined whether improving patient education and closer monitoring via telehealth could improve adherence. Both Waters et al and Nikolaus et al found that a standardized education program alone did not improve medication adherence. ${ }^{58,59}$ In contrast, Elkjaer et al showed that combining disease-specific education with Connected Care, a Web-based telehealth program, for UC patients on 5-ASA led to higher adherence during flares and shorter duration of flares, though it did not change rates of overall adherence. ${ }^{60}$ In a study of IBD patients, de Jong et al demonstrated that the use of myIBDcoach, a similar telehealth program which tracked disease activity and provided e-learning modules, led to increased medication adherence and fewer hospitalizations at 12 months. ${ }^{61}$ However, Cross et al found no difference in medication adherence or disease activity through participation in UC HAT, another telehealth program. ${ }^{62}$
Notably, attrition rates were $24 \%$ (89 out of 117 patients) in Connected Care and $32 \%$ (8 out of 25 patients) in UC HAT, both which required weekly participation by default, compared to only $6 \%$ (27 out of 465 patients) in myIBDcoach, which asked for monthly participation unless a flare was detected. These findings suggest that telehealth programs may need to be convenient for the user or else patients may not adhere to the program, just as they may not adhere to taking medications if it is cumbersome.

There is some evidence to suggest that personalized interventions for improving 5-ASA adherence may lead to positive results. Moshkova et al demonstrated that providing patients with individualized interventions from a menu of choices including dose simplification, pillboxes, visual medication reminders, and mobile phone alerts significantly increased adherence from $32 \%$ to $72 \%(p=0.001)$ at 12 months. ${ }^{63}$ Greenley et al found that while providing problem-solving skills training to adolescent (age 11-18) IBD patients did not improve overall adherence, it did significantly increase adherence among an older subset (age 16-18) of patients with imperfect adherence by $10 \%$ $(p<0.05) .{ }^{64}$ The results from Moshkovska et al and Greenley et al suggest that interventions such as changes in dosing regimen, patient education, telehealth, and other techniques could all be promising if offered to the right patient.

\section{Conclusion}

$\mathrm{UC}$ is a chronic medical condition that requires life-long medication adherence for disease control and prevention of complications. However, adherence to 5-ASA remains low in real-world settings, influenced by a complex interplay of socioeconomic, systems-level, disease-related, and treatment-related factors. While non-adherence remains difficult to address, clinicians may be able to improve 5-ASA adherence by switching formulations, simplifying the dosing, engaging patients with telehealth, and perhaps above all, providing a personalized approach towards tackling the problem. However, several gaps remain in our knowledge about 5-ASA adherence, and further research could confirm the real-world efficacy of dose simplification, investigate other methods to offer personalized strategies for increasing adherence, and explore whether combining multiple strategies can improve 5-ASA adherence, and potentially outcomes, in UC patients. 


\section{Author Contributions}

All authors contributed to data analysis, drafting or revising the article, have agreed on the journal to which the article will be submitted, gave final approval of the version to be published, and agree to be accountable for all aspects of the work.

\section{Funding}

There is no funding to report.

\section{Disclosure}

The authors report no conflicts of interest in this work.

\section{References}

1. Tripathi K, Feuerstein JD. New developments in ulcerative colitis: latest evidence on management, treatment, and maintenance. Drugs Context. 2019;8:212572. doi:10.7573/dic. 212572

2. Truelove SC, Witts LJ. Cortisone in ulcerative colitis; final report on a therapeutic trial. $B r$ Med $J$. 1955;2(4947):1041-1048. doi:10.1136/ bmj.2.4947.1041

3. Schroeder KW, Tremaine WJ, Ilstrup DM. Coated oral 5-aminosalicylic acid therapy for mildly to moderately active ulcerative colitis. A randomized study. $N$ Engl $J$ Med. 1987;317 (26):1625-1629. doi:10.1056/NEJM198712243172603

4. Ko CW, Singh S, Feuerstein JD, et al. AGA clinical practice guidelines on the management of mild-to-moderate ulcerative colitis. Gastroenterology. 2019;156(3):748-764. doi:10.1053/j.gastro.2018.12.009

5. Alatab S, Sepanlou SG, Ikuta K; GBD 2017 Inflammatory Bowel Disease Collaborators. The global, regional, and national burden of inflammatory bowel disease in 195 countries and territories, 1990 2017: a systematic analysis for the global burden of disease study 2017. Lancet Gastroenterol Hepatol. 2020;5(1):17-30. doi:10.1016/ S2468-1253(19)30333-4

6. Murray A, Nguyen TM, Parker CE, Feagan BG, MacDonald JK; Cochrane Gut Group. Oral 5-aminosalicylic acid for maintenance of remission in ulcerative colitis. Cochrane Database Syst Rev. 2020;2020(8). doi:10.1002/14651858.CD000544.pub5

7. Harbord M, Eliakim R, Bettenworth D, et al. Third European evidence-based consensus on diagnosis and management of ulcerative colitis. part 2: current management. J Crohns Colitis. 2017;11 (7):769-784. doi:10.1093/ecco-jcc/jjx009

8. Fumery M, Singh S, Dulai PS, Gower-Rousseau C, Peyrin-Biroulet L, Sandborn WJ. Natural history of adult ulcerative colitis in population-based cohorts: a systematic review. Clin Gastroenterol Hepatol off Clin Pract J Am Gastroenterol Assoc. 2018;16(3):343356.e3. doi:10.1016/j.cgh.2017.06.016

9. Hanauer SB, Sninsky CA, Robinson M, et al. An oral preparation of mesalamine as long-term maintenance therapy for ulcerative colitis. Ann Intern Med. 1996;124(2):204-211. doi:10.7326/0003-4819-1242-199601150-00003

10. Fockens P, Mulder CJ, Tytgat GN, et al; Dutch Pentasa Study Group. Comparison of the efficacy and safety of 1.5 compared with 3.0 $\mathrm{g}$ oral slow-release mesalazine (Pentasa) in the maintenance treatment of ulcerative colitis. Eur J Gastroenterol Hepatol. 1995;7 (11):1025-1030. doi:10.1097/00042737-199511000-00003

11. Green JR, Gibson JA, Kerr GD, et al.; ABACUS Investigator group Maintenance of remission of ulcerative colitis: a comparison between balsalazide $3 \mathrm{~g}$ daily and mesalazine $1.2 \mathrm{~g}$ daily over 12 months. Aliment Pharmacol Ther. 1998;12(12):1207-1216. doi:10.1046/ j.1365-2036.1998.00427.x.
12. Miller NH. Compliance with treatment regimens in chronic asymptomatic diseases. Am J Med. 1997;102(2A):43-49. doi:10.1016/s00029343(97)00467-1

13. Cramer JA. A systematic review of adherence with medications for diabetes. Diabetes Care. 2004;27(5):1218-1224. doi:10.2337/ diacare.27.5.1218

14. van Hees PA, van Tongeren JH. Compliance to therapy in patients on a maintenance dose of sulfasalazine. J Clin Gastroenterol. 1982;4 (4):333-336. doi:10.1097/00004836-198208000-00008

15. Shale MJ, Riley SA. Studies of compliance with delayed-release mesalazine therapy in patients with inflammatory bowel disease. Aliment Pharmacol Ther. 2003;18(2):191-198. doi:10.1046/j.13652036.2003.01648.x

16. D'Incà R, Bertomoro $\mathrm{P}$, Mazzocco K, Vettorato MG, Rumiati R, Sturniolo GC. Risk factors for non-adherence to medication in inflammatory bowel disease patients. Aliment Pharmacol Ther. 2008;27(2):166-172. doi:10.1111/j.1365-2036.2007.03555.x

17. Moshkovska T, Stone MA, Clatworthy J, et al. An investigation of medication adherence to 5-aminosalicylic acid therapy in patients with ulcerative colitis, using self-report and urinary drug excretion measurements. Aliment Pharmacol Ther. 2009;30(11-12):1118-1127. doi:10.1111/j.1365-2036.2009.04152.x

18. Osterberg L, Blaschke T. Adherence to medication. $N$ Engl J Med. 2005;353(5):487-497. doi:10.1056/NEJMra050100

19. Kane SV, Cohen RD, Aikens JE, Hanauer SB. Prevalence of nonadherence with maintenance mesalamine in quiescent ulcerative colitis. Am J Gastroenterol. 2001;96(10):2929-2933. doi:10.1111/ j.1572-0241.2001.04683.x

20. Lachaine J, Yen L, Beauchemin C, Hodgkins P. Medication adherence and persistence in the treatment of Canadian ulcerative colitis patients: analyses with the RAMQ database. BMC Gastroenterol. 2013;13:23. doi:10.1186/1471-230X-13-23

21. Römkens TEH, Te Morsche R, Peters W, Burger DM, Hoentjen F, Drenth JPH. Urinalysis of MMX-mesalazine as a tool to monitor 5-ASA adherence in daily IBD practice. $\mathrm{Br} J$ Clin Pharmacol. 2018;84(3):477-481. doi:10.1111/bcp.13462

22. Kane S, Huo D, Magnanti K. A pilot feasibility study of once daily versus conventional dosing mesalamine for maintenance of ulcerative colitis. Clin Gastroenterol Hepatol off Clin Pract J Am Gastroenterol Assoc. 2003;1(3):170-173. doi:10.1053/cgh.2003.50025

23. Kane S, Huo D, Aikens J, Hanauer S. Medication nonadherence and the outcomes of patients with quiescent ulcerative colitis. Am J Med. 2003;114(1):39-43. doi:10.1016/s0002-9343(02)01383-9

24. Kawakami A, Tanaka M, Nishigaki M, et al. Relationship between non-adherence to aminosalicylate medication and the risk of clinical relapse among Japanese patients with ulcerative colitis in clinical remission: a prospective cohort study. $J$ Gastroenterol. 2013;48 (9):1006-1015. doi:10.1007/s00535-012-0721-x

25. Hjortswang $H$, Järnerot $G$, Curman $B$, et al. The influence of demographic and disease-related factors on health-related quality of life in patients with ulcerative colitis. Eur J Gastroenterol Hepatol. 2003;15(9):1011-1020. doi:10.1097/00042737-200309 000-00012

26. Han SW, McColl E, Barton JR, James P, Steen IN, Welfare MR. Predictors of quality of life in ulcerative colitis: the importance of symptoms and illness representations. Inflamm Bowel Dis. 2005;11 (1):24-34. doi:10.1097/00054725-200501000-00004

27. Vaizey CJ, Gibson PR, Black CM, et al. Disease status, patient quality of life and healthcare resource use for ulcerative colitis in the UK: an observational study. Frontline Gastroenterol. 2014;5 (3):183-189. doi:10.1136/flgastro-2013-100409

28. Watanabe C, Nagahori M, Fujii T, et al. Non-adherence to medications in pregnant ulcerative colitis patients contributes to disease flares and adverse pregnancy outcomes. Dig Dis Sci. 2021;66 (2):577-586. doi:10.1007/s10620-020-06221-6 
29. Moody GA, Jayanthi V, Probert CS, Mac Kay H, Mayberry JF. Long-term therapy with sulphasalazine protects against colorectal cancer in ulcerative colitis: a retrospective study of colorectal cancer risk and compliance with treatment in Leicestershire. Eur J Gastroenterol Hepatol. 1996;8 (12):1179-1183. doi:10.1097/00042737-199612000-00009

30. Velayos FS, Terdiman JP, Walsh JM. Effect of 5-aminosalicylate use on colorectal cancer and dysplasia risk: a systematic review and metaanalysis of observational studies. Am $J$ Gastroenterol. 2005;100(6):1345-1353. doi:10.1111/j.1572-0241.2005.41442.x

31. van Staa TP, Card T, Logan RF, Leufkens HGM. 5-Aminosalicylate use and colorectal cancer risk in inflammatory bowel disease: a large epidemiological study. Gut. 2005;54(11):1573-1578. doi:10.1136/ gut.2005.070896

32. Bassi A, Dodd S, Williamson P, Bodger K. Cost of illness of inflammatory bowel disease in the UK: a single centre retrospective study. Gut. 2004;53(10):1471-1478. doi:10.1136/gut.2004.041616

33. Kane S, Shaya F. Medication non-adherence is associated with increased medical health care costs. Dig Dis Sci. 2008;53 (4):1020-1024. doi:10.1007/s10620-007-9968-0

34. Mitra D, Hodgkins P, Yen L, Davis KL, Cohen RD. Association between oral 5-ASA adherence and health care utilization and costs among patients with active ulcerative colitis. BMC Gastroenterol. 2012;12:132. doi:10.1186/1471-230X-12-132

35. Sabaté E, Sabaté E. Adherence to long-term therapies: evidence for action. World Health Organization; 2003.

36. Ediger JP, Walker JR, Graff L, et al. Predictors of medication adherence in inflammatory bowel disease. Am J Gastroenterol. 2007;102 (7):1417-1426. doi:10.1111/j.1572-0241.2007.01212.x

37. Cervený P, Bortlík M, Kubena A, Vlcek J, Lakatos PL, Lukás M. Nonadherence in inflammatory bowel disease: results of factor analysis. Inflamm Bowel Dis. 2007;13(10):1244-1249. doi:10.1002/ ibd.20189

38. Yen L, Wu J, Hodgkins PL, Cohen RD, Nichol MB. Medication use patterns and predictors of nonpersistence and nonadherence with oral 5-aminosalicylic acid therapy in patients with ulcerative colitis. J Manag Care Pharm JMCP. 2012;18(9):701-712. doi:10.18553/ jmcp.2012.18.9.701

39. Lee J, Jee SR, Kim HW, et al. Factors associated with low adherence to oral 5-aminosalicylic acid in patients with ulcerative colitis. PLoS One. 2019;14(3):e0214129. doi:10.1371/journal.pone.0214129

40. Keil R, Wasserbauer M, Zádorová Z, et al. Adherence, risk factors of nonadherence and patient's preferred treatment strategy of mesalazine in ulcerative colitis: multicentric observational study. Scand $J$ Gastroenterol. 2018;53(4):459-465. doi:10.1080/00365521.20 18.1451915

41. Nguyen GC, LaVeist TA, Harris ML, Wang M-H, Datta LW, Brant SR. Racial disparities in utilization of specialist care and medications in inflammatory bowel disease. Am $\mathrm{J}$ Gastroenterol. 2010;105(10):2202-2208. doi:10.1038/ajg.2010.202

42. Xie Z, St Clair P, Goldman DP, Joyce G, Ruiz JM. Racial and ethnic disparities in medication adherence among privately insured patients in the United States. PLoS One. 2019;14(2):e0212117. doi:10.1371/ journal.pone. 0212117

43. Sun K, Eudy AM, Criscione-Schreiber LG, et al. Racial disparities in medication adherence between African American and Caucasian patients with systemic lupus erythematosus and their associated factors. ACR Open Rheumatol. 2020;2(7):430-437. doi:10.1002/ acr2.11160

44. Sewitch MJ, Abrahamowicz M, Barkun A, et al. Patient nonadherence to medication in inflammatory bowel disease. $\mathrm{Am}$ $J \quad$ Gastroenterol. 2003;98(7):1535-1544. doi:10.1111/j.15720241.2003.07522.x

45. Moshkovska T, Stone M, Baker R, Mayberry J. Qualitative investigation of patient adherence to 5-aminosalicylic acid therapy in patients with ulcerative colitis. Inflamm Bowel Dis. 2008;14(6):763-768. doi:10.1002/ibd.20404
46. Prantera C, Viscido A, Biancone L, Francavilla A, Giglio L, Campieri M. A new oral delivery system for 5-ASA: preliminary clinical findings for MMx. Inflamm Bowel Dis. 2005;11(5):421-427. doi:10.1097/01.mib.0000158386.25660.1e

47. Domino FJ. Improving adherence to treatment for hypertension. $A m$ Fam Physician. 2005;71(11):2089-2090.

48. Coleman CI, Limone B, Sobieraj DM, et al. Dosing frequency and medication adherence in chronic disease. J Manag Care Pharm JMCP. 2012;18(7):527-539. doi:10.18553/jmcp.2012.18.7.527

49. Hawkins T. Impact of once- and twice-daily dosing regimens on adherence and overall safety. AIDS Read. 2004;14(6):320-322, 324, 329-331, 334-336.

50. Recker RR, Gallagher R, MacCosbe PE. Effect of dosing frequency on bisphosphonate medication adherence in a large longitudinal cohort of women. Mayo Clin Proc. 2005;80(7):856-861. doi:10.4065/80.7.856

51. Kamm MA, Lichtenstein GR, Sandborn WJ, et al. Randomised trial of once- or twice-daily MMX mesalazine for maintenance of remission in ulcerative colitis. Gut. 2008;57(7):893-902. doi:10.1136/ gut.2007.138248

52. Dignass AU, Bokemeyer B, Adamek H, et al. Mesalamine once daily is more effective than twice daily in patients with quiescent ulcerative colitis. Clin Gastroenterol Hepatol off Clin Pract J Am Gastroenterol Assoc. 2009;7(7):762-769. doi:10.1016/j.cgh.2009.04.004

53. Sandborn WJ, Korzenik J, Lashner B, et al. Once-daily dosing of delayed-release oral mesalamine (400-mg tablet) is as effective as twice-daily dosing for maintenance of remission of ulcerative colitis. Gastroenterology. 2010;138(4):1286-1296, 1296.e1-3. doi:10.1053/j. gastro.2009.12.054

54. Kruis W, Kiudelis G, Rácz I, et al. Once daily versus three times daily mesalazine granules in active ulcerative colitis: a double-blind, double-dummy, randomised, non-inferiority trial. Gut. 2009;58 (2):233-240. doi:10.1136/gut.2008.154302

55. Flourié $B$, Hagège $H$, Tucat $G$, et al. Randomised clinical trial: once- vs. twice-daily prolonged-release mesalazine for active ulcerative colitis. Aliment Pharmacol Ther. 2013;37(8):767-775. doi:10.1111/apt.12266

56. Tong JL, Huang ML, Xu XT, Qiao YQ, Ran ZH. Once-daily versus multiple-daily mesalamine for patients with ulcerative colitis: a meta-analysis. J Dig Dis. 2012;13(4):200-207. doi:10.1111/j.17512980.2012.00576.x

57. Li W, Zhang Z-M, Jiang X-L. Once daily vs multiple daily mesalamine therapy for mild to moderate ulcerative colitis: a meta-analysis. Colorectal Dis off J Assoc Coloproctology G B Irel. 2016;18(7): O214-223. doi:10.1111/codi.13393

58. Waters BM, Jensen L, Fedorak RN. Effects of formal education for patients with inflammatory bowel disease: a randomized controlled trial. Can J Gastroenterol J Can Gastroenterol. 2005;19(4):235-244. doi: $10.1155 / 2005 / 250504$

59. Nikolaus S, Schreiber S, Siegmund B, et al. Patient education in a 14-month randomised trial fails to improve adherence in ulcerative colitis: influence of demographic and clinical parameters on non-adherence. J Crohns Colitis. 2017;11(9):1052-1062. doi:10.1093/ecco-jcc/jjx062

60. Elkjaer M, Shuhaibar M, Burisch J, et al. E-health empowers patients with ulcerative colitis: a randomised controlled trial of the webguided "Constant-care" approach. Gut. 2010;59(12):1652-1661. doi:10.1136/gut.2010.220160

61. de Jong MJ, van der Meulen-de Jong AE, Romberg-Camps MJ, et al. Telemedicine for management of inflammatory bowel disease (myIBDcoach): a pragmatic, multicentre, randomised controlled trial. Lancet Lond Engl. 2017;390(10098):959-968. doi:10.1016/ S0140-6736(17)31327-2

62. Cross RK, Cheevers N, Rustgi A, Langenberg P, Finkelstein J. Randomized, controlled trial of home telemanagement in patients with ulcerative colitis (UC HAT). Inflamm Bowel Dis. 2012;18 (6):1018-1025. doi:10.1002/ibd.21795 
63. Moshkovska T, Stone Ma, Smith RM, Bankart J, Baker R, Mayberry JF. Impact of a tailored patient preference intervention in adherence to 5-aminosalicylic acid medication in ulcerative colitis: results from an exploratory randomized controlled trial. Inflamm Bowel Dis. 2011;17(9):1874-1881. doi:10.1002/ibd.21570

64. Greenley RN, Gumidyala AP, Nguyen E, et al. Can you teach a teen new tricks? Problem solving skills training improves oral medication adherence in pediatric patients with inflammatory bowel disease participating in a randomized trial. Inflamm Bowel Dis. 2015;21 (11):2649-2657. doi:10.1097/MIB.0000000000000530
65. Tenjarla S. Dissolution of commercially available mesalamine formulations at various pH levels. Drugs RD. 2015;15(2):211-215. doi:10.1007/s40268-015-0097-5

\section{Publish your work in this journal}

Clinical and Experimental Gastroenterology is an international, peerreviewed, open access, online journal publishing original research, reports, editorials, reviews and commentaries on all aspects of gastroenterology in the clinic and laboratory. This journal is indexed on American Chemical Society's Chemical Abstracts Service (CAS)
The manuscript management system is completely online and includes a very quick and fair peer-review system, which is all easy to use. Visit http://www.dovepress.com/testimonials.php to read real quotes from published authors. 